\title{
Wind Farm Optimum Efficiency by Voltage Control
}

\author{
J.M. Roldán Fernández ${ }^{1}$, M.A. Caballero Gutierrez ${ }^{1}$, A.G. González Rodríguez ${ }^{2}$ and M. Burgos Payán ${ }^{1}$ \\ ${ }^{1}$ Department of Electrical Engineering, University of Seville \\ Camino de los Descubrimientos, s/n - 41092 Sevilla, Spain \\ phone: +34 954487283 - fax: +34954 487284 - e-mail: $\underline{\text { mburgos@us.es }}$ \\ ${ }^{2}$ Department of Electronic, University of Jaén \\ Escuela Politécnica Superior - Campus "Las Lagunillas" - 23071 Jaén, Spain \\ phone: +34953212424 - fax: +34953212400 - e-mail: agaspar@ujaen.es
}

\begin{abstract}
The basic idea of improving both the power factor and the efficiency of induction motors at partial or light load reducing the supply voltage was patented by $\mathrm{F}$. Nola, in the late 70's of the last century. This energy saving and power factor improvement strategy work better with small power (less efficient) motor and long periods of time with partial or light load under $25-30 \%$ of the rated power.
\end{abstract}

These improvements can be applied to the induction generators (induction machines performing as generators), were long periods of low wind speed and low level of generated power are very common. In fact, this technique is more suitable for induction generators than for motors. The soft-starter used to soften the connection transients can be used to supply the wind farm induction generators at reduced voltage during low wind speed periods. This way, more power and reactive power will be available to be injected in the transmission and distribution network at no additional cost.

\section{Key words}

Wind power, induction generators, minimum losses, optimum power factor, voltage control, soft-starter.

\section{Introduction}

The basic idea of improving both the power factor and the efficiency of induction motors at partial or light load reducing the supply voltage was patented by F. Nola, in the late 70's of the last century [1]. This energy saving and power factor improvement strategy work better with small power (less efficient) motor and long periods of time with partial or light load under $25-30 \%$ of the rated power.

A basic profitability investment analysis shows that the save in the electric bill (due to the energy saved reducing the motor supply voltage) must pay for the investment in the voltage controller device. So, very often, the application of this kind of saving devices is limited by a very long period of pay back.

Although these improvements are firstly focused on induction motors, can be applied to the induction generators (induction machines performing as generators). In a wind farm, long periods of low wind speed and low level of generated power are very common. This is a very well suited situation for potential induction generator performance improvement by voltage reduction. In fact, the voltage reduction is a technique more suitable for induction generators than for motors, as will be shown later. The soft-starter device used to soften both the connection and disconnection transients can be used to supply the wind farm induction generators at reduced voltage during the low wind speed periods. This way, more power and reactive power could be available to be injected in the transmission and distribution network at no additional cost.

\section{Efficiency and power factor}

Nowadays the share of generation based on renewable energy sources in the mix of the electrical energy has grown in a spectacular way with regard to conventional fossil energies. This is mainly due to a few factors such as the high and growing prices of the traditional fossil fuels, a bigger social environmental concern (Kyoto protocol and E.U. white book) and institutional support (feed-in tariffs) in order to save energy and reduce foreign fossil fuel dependence, among others. Focusing on the types of renewable energy, it is a well-known fact that the wind energy has experienced the highest growth. As an example, in Spain, at the end of the year 2004, there were $8.2 \mathrm{GW}$ wind power installed and operating. In the European Union there were $30.1 \mathrm{GW}$ at the same date, and $40 \mathrm{GW}$ are planned for 2010 . That is why the development of an effective tool for improving the wind farm efficiency and power factor has a special relevance. One of the drawbacks of these kind of renewable power plants is the low number of equivalent (rated load) utilization hours. In the year 2004, the mean value in Spain was 2350 equivalent utilization hours $(27 \%$ of the potential 8760 hours/year). This means a lot of time generating at partial or light load.

Although at rated full load both the efficiency and the power factor of an induction motor are high $\left(\eta_{R F L} \approx 0.90\right.$ $0.95, P F_{R F L} \approx 0.85-0.9$ for a $100 \mathrm{~kW}$ motor), those figures fall at light load $\left(P<0.25-0.30 P_{R F L}\right)$. 
The three main components of induction motors losses are copper losses, iron losses and mechanical (friction and windage) losses. All these losses add up to the total amount of the motor losses. Since the speed of an induction motor is almost constant (not dependent of the load), the mechanical losses (speed dependent) are almost constant (and small) and can not be avoided. The iron losses are (squared) voltage dependent and so they can be reduced supplying the motor with a reduced voltage. The copper losses $\left(\sum R I^{2}\right)$ are shaft load dependant.

For a $100 \mathrm{~kW}$ motor, at rated full load, the iron losses are $25-40 \%$ of the total losses, while the no load current is $30-60 \%$ of the rated full load current. So, at light loads (loads under $25-30 \%$ of the rated power), there is a potential for improving both the efficiency and the power factor by reducing the supply voltage. A supply voltage reduction decreases the iron losses (with the voltage square) and the magnetizing current (reactive component and flux, linearly with the voltage) but, to drive the load torque, increases the active component of the current and the copper losses.

The basic idea of improving both the power factor and the efficiency of induction motor at partial or light load reducing the supply voltage by was patented by F. Nola, in the late 70's of the last century [1]. This improvement is higher for small power motors, with lower efficiency, and situations where the induction machine is working at partial or light load $\left(P<0.25-0.30 P_{R F L}\right)$ for long periods of time [2-6]. For an induction generator (induction machine in generator mode) this voltage control strategy can be applied with even better results. The analysis is as follows. At low wind speed or low power generation conditions, the induction generator rotor speed is almost equal to the synchronous one. Due to the small value of the slip, the effective rotor resistance, $R_{2} / s$, is bigger than the rotor reactance, $X_{2}$, or the locked rotor impedance, $X_{L R}=X_{1}+X_{2}$. Therefore, the effective rotor resistance becomes the main component of the rotor effective impedance, $\boldsymbol{Z}_{2}(s)$, and the total input impedance, $\boldsymbol{Z}(s)$. This situation let us consider the rotor current, $\boldsymbol{I}_{2}$, almost in phase with the electromotive force, $\boldsymbol{E}$, or even the voltage, $\boldsymbol{U}$. This is supported by two issues:

- Due to the high effective rotor resistance, the real component of the stator current is low, thus not increasing significantly the stator current with respect to the no load one, $\left|\boldsymbol{I}_{0 p u}\right| \approx 0.4-0.6$.

- The real component of the stator component does not produce a high voltage drop at the stator impedance, which is mostly reactive. Therefore, the stator impedance voltage drop is small, $\quad\left|Z_{1} I_{\boldsymbol{0}}\right|<<|\boldsymbol{U}|$, and the electromotive force is almost equal to the supply voltage, $\boldsymbol{E} \approx \boldsymbol{U}$.

At that low wind speed conditions, both the electromagnetic torque and the air gap power $\left(P_{a}=T_{i} \Omega_{l}=3 \cdot \operatorname{Re}\left(\boldsymbol{E} \cdot \mathbf{I}_{2}{ }^{*}\right)\right)$ are almost proportional to the product $|\boldsymbol{E}| \cdot\left|\boldsymbol{I}_{2}\right|\left(P_{a}=T_{i} \Omega_{1} \approx 3 E \cdot I_{2}\right)$ or, even, to the product $U \cdot\left|\mathbf{I}_{2}\right|\left(P_{a}=T_{i} \Omega_{1} \approx 3 \cdot U \cdot I_{2} \approx 3 \cdot U^{2} \cdot \mathrm{s} / R_{2}\right)$. Thus, for an approximate analysis, the circuit model shown in Fig. 1 can be considered.

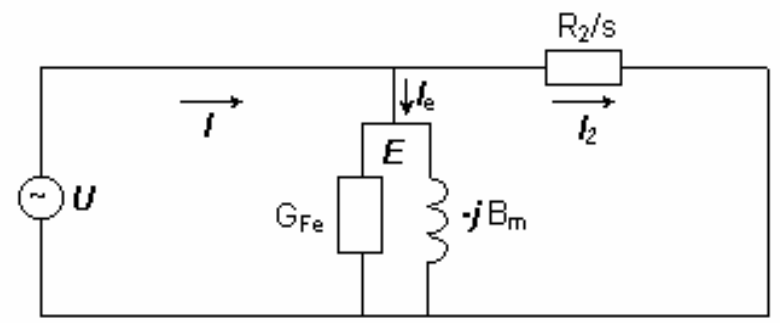

Fig. 1. Simplified circuit model for an induction generator at low wind speed conditions.

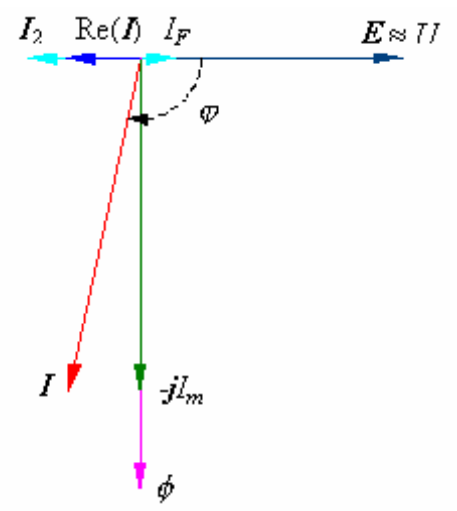

Fig. 2. Simplified phasor diagram for an induction generator at low wind speed conditions.

Figure 2 shows a phasor diagram for this low wind speed or light power conditions. As previously mentioned, reducing the supply voltage will increase the power factor and the power efficiency.

Figure 3 shows the phasor diagram resultant after reducing the supply voltage to $U^{\prime}=U / k$, with a factor $k>1$ (but near one) and with a constant level of generated power $P_{a}$.

If the voltage reduction is small $(k \approx 1)$, the stator current decreases since its reactive component does. The stator copper losses are also reduced with the square of the magnetizing current

$$
P_{J 1}=3 R_{1}\left|\boldsymbol{I}_{1}\right|^{2}
$$

Thus, the increase of rotor copper losses is broadly compensated by iron and the stator copper losses, leading to a net total losses reduction. As can be seen, the stator current both reduces its modulus and improves the power factor.

At these conditions the slip and the rotor current can be calculated as:

$$
\begin{aligned}
& S \approx \frac{P_{a} R_{2}}{3 U^{2}} \\
& I_{2} \approx \frac{U}{R_{2}} S
\end{aligned}
$$


So, the apparent power, the total losses, the reactive power, the power factor and the efficiency, can be expressed as:

$$
\begin{aligned}
& \boldsymbol{S}=3 U \boldsymbol{I}^{*}=P+\mathbf{j} Q \approx P_{a}+3 G_{F e} U^{2}+\mathbf{j} 3 B_{m} U^{2} \\
& P_{p} \approx\left(R_{1}+R_{2}\right) \frac{P_{a}{ }^{2}}{3 U^{2}}+3 R_{1}\left|\boldsymbol{Y}_{\boldsymbol{e}}\right|^{2} U^{2}+3 G_{F e} U^{2} \\
& +2 G_{F e} R_{1} P_{a}+P_{m e c}(\Omega)=P_{p}\left(U, P_{a}\right) \\
& Q \approx\left(X_{1}+X_{2}\right) \frac{P_{a}{ }^{2}}{3 U^{2}}+3 X_{1}\left|\boldsymbol{Y}_{\boldsymbol{e}}\right|^{2} U^{2}+3 B_{m} U^{2} \\
& +2 G_{F e} R_{1} P_{a}=Q\left(U, P_{a}\right) \\
& F P=\cos \varphi_{1} \approx \frac{R_{F e} P_{a}+3 U^{2}}{\sqrt{\left(R_{F e} P_{a}+3 U^{2}\right)^{2}+\left(3 U^{2} R_{F e}\right)^{2}}}
\end{aligned}
$$

So, using new constants $(A, B, C, D, E$ and $F)$, the total power losses and the reactive power, can be written as:

$$
\begin{aligned}
& P_{p} \approx A \frac{P_{a}^{2}}{U^{2}}+B U^{2}+C P_{a}+P_{m e c}(\Omega) \\
& Q \approx D \frac{P_{a}^{2}}{U^{2}}+E U^{2}+F P_{a} \\
& A=\frac{R_{1}+R_{2}}{3} \quad B=3\left(R_{1}\left|\boldsymbol{Y}_{\boldsymbol{e}}\right|^{2}+G_{F e}\right) \quad C=2 G_{F e} R_{1} \\
& D=\frac{X_{1}+X_{2}}{3} \quad E=3\left(X_{1}\left|\boldsymbol{Y}_{\boldsymbol{e}}\right|^{2}+B_{m}\right) \quad F=2 G_{F e} R_{1}
\end{aligned}
$$

As can be seen, both the total losses and the reactive power are functions of the voltage supply, $U$, and the level of generated power, $P_{a}$. In the losses expression there are two terms (squared) voltage dependent and two other dependent of the level of generated power, $P_{a}$. The first term (proportional to the electromagnetic torque or to the air-gap power and inversely proportional to the squared voltage) explains the component of the stator copper loss due to the active component of the stator current (equal to the rotor current) and the rotor copper loss. The second term (proportional to the square voltage) is the component of the stator copper loss cue to the excitation current (mainly reactive) and the iron losses. The third term (proportional a $\left.P_{a}\right)$ is a component of the stator copper loss that must negative $\left(P_{a}<0\right)$ for generation performance.

\section{Reduced voltage performance}

Figure 3 shows the phasor diagram resultant after reducing the supply voltage to $U^{\prime}=U / k$, with the factor $k>1$, but near one, with a constant level of generated power $\left(P_{a}=\right.$ Constant). Reducing the supply voltage by a factor $k$, means a growing of the slip with the squared $k$ factor $\left(s^{\prime}=k^{2} s\right)$, because:

$s^{\prime}=s\left(U^{\prime}\right) \approx \frac{P_{a} R_{2}}{3 U^{\prime 2}}=\frac{P_{a} R_{2}}{3(U / k)^{2}}=k^{2} s(U)$

The rotor current must grow by this same factor in order to keep the electromagnetic torque value $\left(I_{2}{ }^{\prime}=k I_{2}\right)$.

$$
\boldsymbol{I}_{2}^{\prime}=\boldsymbol{I}_{2}\left(U^{\prime}\right) \approx \frac{P_{a}}{3 U^{\prime}}=\frac{P_{a}}{3(U / k)}=k \boldsymbol{I}_{2}
$$

This will grow the rotor copper losses. On the other hand, the voltage reduction the voltage reduction will produces a squared reduction of the iron losses $\left(P_{F e}{ }^{\prime}=P_{F e} / k^{2}\right)$.

$$
P_{F e}{ }^{\prime}=P_{F e}\left(U^{\prime}\right) \approx 3 G_{F e}(U / k)^{2}=k P_{F e}
$$

The excitation current will be reduced too $\left(I_{e}{ }^{\prime}=I_{e} / k\right.$ $\left.=I_{F e} / k-\mathbf{j} I_{m} / k\right)$.

$$
\begin{aligned}
& \boldsymbol{I}_{\boldsymbol{e}}^{\prime}=\boldsymbol{I}_{\boldsymbol{e}}\left(U^{\prime}\right) \approx \boldsymbol{Y}_{\boldsymbol{e}} U / k=\boldsymbol{I}_{\boldsymbol{e}}(U) / k=\boldsymbol{I}_{\boldsymbol{e}} / k \\
& \boldsymbol{I}_{1}^{\prime}=\boldsymbol{I}_{2}{ }^{\prime}+\boldsymbol{I}_{e}{ }^{\prime} \approx k \boldsymbol{I}_{2}+\boldsymbol{I}_{\boldsymbol{e}} / k
\end{aligned}
$$

If the voltage reduction is small $(k \approx 1)$, the current magnetization (reactive), been much bigger than the rotor current (active), mainly influences the stator current variation, that reduces it size. This current reduction reduces the stator copper losses. So, the increment of rotor copper losses is broadly compensated by iron (magnetic) and the stator copper losses, leading to a net total losses reduction. As can be seen, the stator current both reduces it modulus and improves the power factor.

The voltage reduction factor, $k$, which minimizes the stator current modulus, can be set annulling the current derivative.

$$
\begin{aligned}
& \frac{d\left|\boldsymbol{I}^{\prime}\right|}{d k}=\frac{d\left|\boldsymbol{I}^{\prime}\right|^{2}}{d k} \frac{1}{2\left|\boldsymbol{I}^{\prime}\right|}=\left(k\left|\boldsymbol{I}_{2}\right|^{2}-\frac{\left|\boldsymbol{I}_{\boldsymbol{e}}\right|^{2}}{k^{3}}\right) \frac{1}{2\left|\boldsymbol{I}^{\prime}\right|}=0 \\
& k\left(\left|\boldsymbol{I}_{\text {min }}{ }^{\prime}\right|\right)=\sqrt{\frac{\left|\boldsymbol{I}_{e}\right|}{\left|\boldsymbol{I}_{2}\right|}}
\end{aligned}
$$

If the voltage reduction is great $(k » 1)$, the situation could be as shown in Fig. 4. Now the reduction of the magnetization current does not get to compensate the increase of the rotor current, that is why the stator current grows back, increasing the stator Copper losses. In this case, the increase of the stator and rotor copper losses are not compensated by the reduction of the iron (magnetic) losses, and as a result, a growth of the total losses takes place. It can also be seen that, although the stator current grows, its power factor improves continuously with the voltage reduction.

Therefore, reducing the feeding voltage (network) progressively to an induction generator, working with reduced charge (low wind speed), at the beginning, a reduction of the stator current can be observed (the greater reduction of the excitation current dominates the smaller increase of the rotor current), accompanied by an improvement of the power factor and a reduction of the total losses (the reduction of the stator, iron and copper losses is greater than the increase of copper losses in the rotor). For a certain voltage reduction the minimum losses take place. 


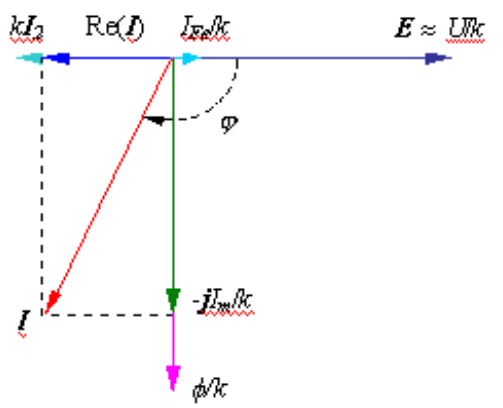

Fig. 3. Simplified phasor diagram for an induction generator at low wind speed conditions and reduced voltage supply.

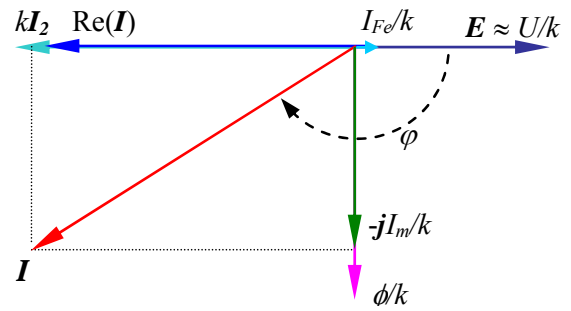

Fig. 4. Simplified phasor diagram for an induction generator at low wind speed conditions and very reduced voltage supply.

Later voltage reductions leads to a growing of the total losses (the reduction of losses in the iron does not compensate the increase of copper losses). The stator current also increases; however, the power factor continuously increases with the voltage reduction.

The value of the voltage that minimizes the losses can be obtained annulling the losses derivative with respect to the tension (or to the voltage squared). Although the mechanical losses vary, approximately, with the cubic of the speed, it can be considered (in a first approximate analysis) that remains constant, since the rotor speed variations (surrounding the synchronous speed) will be very small at low speed winds. So, considering a constant value for the mechanical losses, results:

$$
\frac{d P_{p}}{d U}=\frac{d P_{p}}{d U^{2}} 2 U=\left(-\frac{A P_{a}^{2}}{U^{4}}+B\right) 2 U=0
$$

So, the voltage that minimizes the losses is:

$$
\begin{aligned}
& U\left(P_{p \min }\right)=\sqrt[4]{\frac{A}{B} \sqrt{\left|P_{a}\right|}=K_{U} \sqrt{\left|P_{a}\right|}} \\
& K_{U}=\sqrt[4]{\frac{A}{B}}=\sqrt[4]{\frac{R_{1}+R_{2}}{9\left(R_{1}\left|\boldsymbol{Y}_{\boldsymbol{e}}\right|^{2}+G_{F e}\right)}}
\end{aligned}
$$

With this voltage supply, the losses reach the minimum value:

$$
\begin{aligned}
P_{p \min }= & P_{p}\left(U_{o p t}\right) \approx 2 A \frac{P_{a}^{2}}{U_{o p t}^{2}}+C P_{a}+P_{m e c}= \\
& \left(\frac{2 A}{K^{2}}+C\right) P_{a}+P_{\text {mec }}=(2 \sqrt{A B}+C) P_{a}+P_{\text {mec }}
\end{aligned}
$$

The corresponding values for slip, power factor and efficiency are:

$$
\begin{aligned}
s\left(P_{p \text { min }}\right) \approx & \frac{P_{a} R_{2}}{3\left(U\left(P_{p \min }\right)\right)^{2}}=\frac{R_{2}}{3 K^{2}}=\frac{R_{2}}{3} \sqrt{\frac{B}{A}}= \\
R_{2} \sqrt{\frac{R_{1}\left|\boldsymbol{Y}_{e}\right|^{2}+G_{F e}}{R_{1}+R_{2}}} & \\
F P\left(P_{p \text { min }}\right)= & \cos \varphi_{1}\left(P_{p \min }\right) \approx \\
& \frac{R_{F e} P_{a}+3 U^{2}}{\sqrt{\left(R_{F e} P_{a}+3 U^{2}\right)^{2}+\left(3 U^{2} R_{F e}\right)^{2}}}= \\
\eta_{\text {Generator }}= & 1+\frac{R_{F e}+3 K_{U}^{2}}{\left.P_{M E C H A N I C A L}+3 K_{U}^{2}\right)^{2}+\left(3 K_{U}^{2} R_{F e}\right)^{2}} \\
& 1-\frac{(2 \sqrt{A B}+C) P_{a}+P_{m e c}}{P_{a}\left(1-\frac{R_{2}}{3} \sqrt{\frac{B}{A}}\right)-P_{\text {mec }}} \\
P_{M E C H A N I C A L} & <P<0 \quad(s<0)
\end{aligned}
$$

As can be seen, at the optimum voltage, the slip and the power factor are constants and they are not function of the electromagnetic torque or the air-gap power or the voltage.

As in any linear circuit, the currents and voltages are proportional to the voltage supply and the powers (including the power losses and the reactive power) are proportional to the voltage squared. This way:

$$
\begin{aligned}
& \boldsymbol{I}_{\boldsymbol{k}}=\boldsymbol{f}_{\boldsymbol{k}}(s) U \Rightarrow \boldsymbol{I}_{\boldsymbol{k}}\left(U_{o p t}\right) \approx \boldsymbol{f}_{\boldsymbol{k}}\left(s\left(U_{o p t}\right)\right) K_{U} \sqrt{\left|P_{a}\right|} \\
& P_{\boldsymbol{k}}=\left|\boldsymbol{g}_{\boldsymbol{k}}(s)\right| U^{2} \Rightarrow P_{\boldsymbol{k}}\left(U_{o p t}\right) \approx\left|\boldsymbol{g}_{\boldsymbol{k}}\left(s\left(U_{o p t}\right)\right)\right| K_{U}^{2} P_{a}
\end{aligned}
$$

So, supplying with the minimum losses voltage, the current will vary with the air-gap power squared root or the electromagnetic torque squared root, while the powers will do linearly. The losses expression shows too that for each voltage supply value there is an air-gap power or electromagnetic torque that minimizes the losses. This value is:

$$
\begin{aligned}
& \frac{d P_{p}}{d P_{a}}=\frac{2 A P_{a}^{2}}{U^{2}}+C=0 \\
& P_{a}\left(P_{p \text { min }}\right)=-\frac{C U^{2}}{2 A}
\end{aligned}
$$


As can be see, the minus sign means that this situation corresponds to a generator mode performance. For that level of generated power, the minimum value of the losses is:

$$
P_{p \min } \approx\left(P_{a}-2\right) \frac{A P_{a}}{U^{2}}+B U^{2}+P_{m e c}
$$

An other optimum voltage supply for minimum reactive power demand will be shown.

The value of the voltage that minimizes the reactive power can also be obtained annulling the reactive power derivative with respect to the tension (or to the voltage squared). This way results:

$$
\begin{aligned}
& \frac{d Q}{d U}=\frac{d Q}{d U^{2}} 2 U=\left(-\frac{D P_{a}^{2}}{U^{4}}+E\right) 2 U=0 \\
& U\left(Q_{p \min }\right)=\sqrt[4]{\frac{D}{E} \sqrt{\left|P_{a}\right|}=K_{Q} \sqrt{\left|P_{a}\right|}} \\
& K_{Q}=\sqrt[4]{\frac{D}{E}}=\sqrt[4]{\frac{X_{1}+X_{2}}{9\left(X_{1}\left|\boldsymbol{Y}_{\boldsymbol{e}}\right|^{2}+G_{F e}\right)}}
\end{aligned}
$$

With this optimum voltage, the reactive power reaches its minimum value:

$$
Q_{\min } \approx 2 D \frac{P_{a}^{2}}{\left(U\left(Q_{\text {min }}\right)\right)^{2}}+F=\frac{2 D}{K_{Q}^{2}}\left|P_{a}\right|+F
$$

The corresponding values for slip and power factor are:

$$
\begin{aligned}
& s\left(Q_{\text {min }}\right) \approx \frac{P_{a} R_{2}}{3\left(U\left(Q_{p \text { min }}\right)\right)^{2}}=\frac{R_{2}}{3 K_{Q}^{2}}=\frac{R_{2}}{3} \sqrt{\frac{D}{E}}= \\
& R_{2} \sqrt{\frac{X_{1}\left|Y_{e}\right|^{2}+G_{F e}}{X_{1}+X_{2}}} \\
& F P\left(Q_{\text {min }}\right)=\cos \varphi_{1}\left(Q_{\text {min }}\right) \approx \\
& \frac{R_{F e} P_{a}+3\left(U\left(Q_{\min }\right)\right)^{2}}{\sqrt{\left(R_{F e} P_{a}+3\left(U\left(Q_{\min }\right)\right)^{2}\right)^{2}+\left(3\left(U\left(Q_{\min }\right)\right)^{2} R_{F e}\right)^{2}}}= \\
& \frac{R_{F e}+3 K_{Q}^{2}}{\sqrt{\left(R_{F e}+3 K_{Q}^{2}\right)^{2}+\left(3 K_{Q}^{2} R_{F e}\right)^{2}}}
\end{aligned}
$$

As can be seen, at the optimum voltage, the slip and the power factor are constants and they are not function of the electromagnetic torque or the air-gap power or the voltage.

\section{Optimum generator performance}

The histogram of the wind speed of a potential location for a wind farm is derived from long-term wind speed data (one or more years), taking into account the seasonal and year-by-year wind variations. This data, collected by a temporary meteorological mast, and measured at a certain height above ground level, $h_{r}$, must be extrapolated to the considered tower height, $h$, with the function [7]:

$$
v(h)=v_{r}\left(\frac{h}{h_{r}}\right)^{\alpha}
$$

In this expression $v_{r}$ is the wind speed at the reference height (measured data) and $\alpha$ is the ground rugosity coefficient.

The wind speed histogram (frequency or percentage of time) is approximated by a continuous function called the probability density function, $p(v)$. This function expresses the probability (frequency) of occurrence of wind speed, $v$. Usually a Weibull function is used to model the probability density function [7-9]:

$$
p(v)=\frac{K}{C}\left(\frac{v}{C}\right)^{K-1} \exp \left(-\left(\frac{v}{C}\right)^{K}\right)
$$

Here the constants $C$ and $K$ are the scale and shape parameters, respectively.

The cumulative Weibull distribution, $P(v)$, gives the probability of the wind speed exceeding a certain value, $v$, and can expressed as

$$
P(v)=\exp \left(-\left(\frac{v}{C}\right)^{K}\right)
$$

The the scale and shape parameters $(C$ and $K)$ for the Weibul function can be easily fitted to the wind speed data (extrapolated to the tower height) plotting $\ln v$ against $\ln (-\ln (P(v))$ as a straight (regression) line. Taking logarithms of the cumulative Weibull distribution function twice, results:

$$
\ln (-\ln (P(v)))=k \ln \left(\frac{v}{C}\right)=k \ln v-k \ln C
$$

The shape parameter, $K$, is equal to the slope of the fitted regression line and scale parameter, $C$, is equal to the speed $v^{*}$, where $\ln \left(-\ln \left(P\left(v^{*}\right)\right)\right.$ is zero.

Finally, the calculation of the yearly electric energy generated by a wind-farm can be made combining the long-term wind speed distribution and the specific curve power versus wind speed, $P_{G e n}(v)$, for every wind generator type considered in the wind farm.

Figure 5 shows a Weibull approximation of the wind speed histogram (frequency or percentage of time) for a potential wind farm location, measured at $60 \mathrm{~m}$ height (the intended wind power turbine height). The scale and shape parameter are $C=7.49999 \mathrm{~m} / \mathrm{s}$ and $K=1.49$, respectively.

The variations in wind speed across the wind-farm could be estimated using terrain models that take into account 
both local topography and the shadow effect of the adjacent wind turbines.

Figure 6 shows the normalized power as a function of the wind speed for a $660 \mathrm{~kW}$ wind turbine.

In order to determine the yearly energy saving, first, the relation between the turbine mechanical power and the wind speed generator must be set. A two steep procedure can be used to set this relationship:

- Calculate the values of the slip that corresponds to every produced power.

- Once obtained the slip, calculate the turbine mechanical power responsible for this slip.

Table I shows the slip and turbine mechanical power for every value of the wind speed.

For every value of the turbine mechanical power an initial sliding and the tension that minimizes the losses can be calculated. Obviously, as the voltage varies, the previously used values of applied mechanical power are related to new slip values, as shown in Table II.

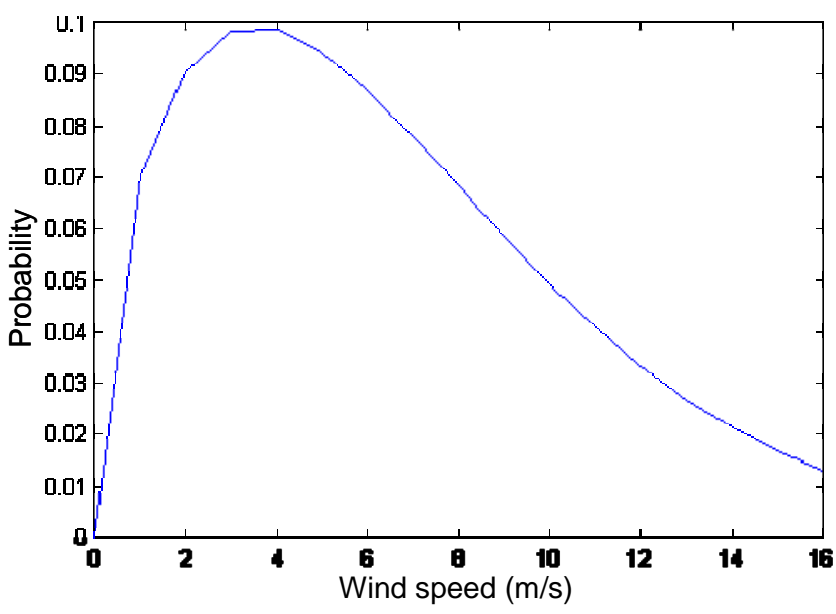

Fig. 5. Weibull distribution of the wind speed histogram for a potential wind farm location.

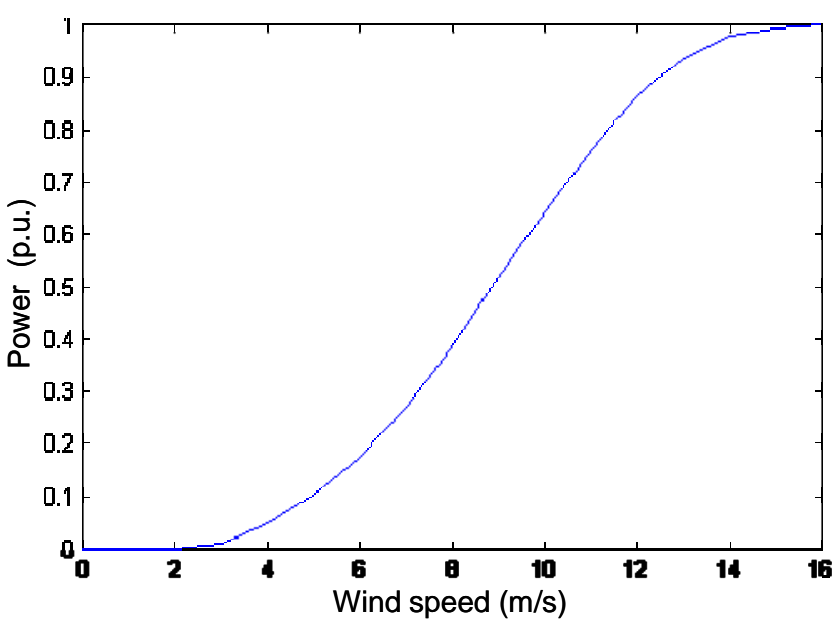

Fig. 6. Wind turbine generator normalized power as a function of the wind speed.
Table I. Values of the slip and mechanical power for every value of wind speed.

\begin{tabular}{|c|c|c||c|c|c|}
\hline $\begin{array}{c}\text { Wind } \\
\text { Speed } \\
(\mathrm{m} / \mathrm{s})\end{array}$ & $\begin{array}{c}\text { Slip } \\
\text { (p.u.) }\end{array}$ & $\begin{array}{c}\text { Wind } \\
\text { Turbine } \\
\text { Power } \\
\text { (p.u.) }\end{array}$ & $\begin{array}{c}\text { Wind } \\
\text { Speed } \\
(\mathrm{m} / \mathrm{s})\end{array}$ & $\begin{array}{c}\text { Slip } \\
\text { (p.u.) }\end{array}$ & $\begin{array}{c}\text { Wind } \\
\text { Turbine } \\
\text { Power } \\
\text { (p.u.) }\end{array}$ \\
\hline 1 & 0 & 0 & 9 & -0.0030 & 0.4225 \\
\hline 2 & 0 & 0 & 10 & -0.0040 & 0.5543 \\
\hline 3 & 0 & 0 & 11 & -0.0049 & 0.6842 \\
\hline 4 & -0.0003 & 0.0409 & 12 & -0.0058 & 0.8047 \\
\hline 5 & -0.0006 & 0.0798 & 13 & -0.0065 & 0.9088 \\
\hline 6 & -0.0010 & 0.1332 & 14 & -0.0071 & 0.9864 \\
\hline 7 & -0.0015 & 0.2057 & 15 & -0.0074 & 1.0284 \\
\hline
\end{tabular}

Table II. Values of the slip and mechanical power for every value of wind speed at the optimum reduced voltage.

\begin{tabular}{|c|c||c|c|}
\hline $\begin{array}{c}\text { Wind } \\
\text { Speed } \\
(\mathrm{m} / \mathrm{s})\end{array}$ & $\begin{array}{c}\text { Generated } \\
\text { Power } \\
(\mathrm{p} . \mathrm{u})\end{array}$ & $\begin{array}{c}\text { Wind } \\
\text { Speed } \\
(\mathrm{m} / \mathrm{s})\end{array}$ & $\begin{array}{c}\text { Generated } \\
\text { Power } \\
(\mathrm{p} . \mathrm{u})\end{array}$ \\
\hline 1 & 0 & 9 & 0.4059 \\
\hline 2 & 0 & 10 & 0.5321 \\
\hline 3 & 0 & 11 & 0.6562 \\
\hline 4 & 0.0092 & 12 & 0.7711 \\
\hline 5 & 0.0481 & 13 & 0.8701 \\
\hline 6 & 0.1282 & 14 & 0.9437 \\
\hline 7 & 0.1980 & 15 & 0.9838 \\
\hline 8 & 0.2912 & 16 & 0.9986 \\
\hline
\end{tabular}

Table III. Values of the slip and mechanical power for every value of wind speed at the optimum reduced voltage including soft starter losses.

\begin{tabular}{|c|c||c|c|}
\hline $\begin{array}{c}\text { Wind } \\
\text { Speed } \\
(\mathrm{m} / \mathrm{s})\end{array}$ & $\begin{array}{c}\text { Generated } \\
\text { Power } \\
(\mathrm{p} . \mathrm{u})\end{array}$ & $\begin{array}{c}\text { Wind } \\
\text { Speed } \\
(\mathrm{m} / \mathrm{s})\end{array}$ & $\begin{array}{c}\text { Generated } \\
\text { Power } \\
(\mathrm{p} . \mathrm{u})\end{array}$ \\
\hline 1 & 0 & 9 & 0.3977 \\
\hline 2 & 0 & 10 & 0.5213 \\
\hline 3 & 0 & 11 & 0.6429 \\
\hline 4 & 0.0092 & 12 & 0.7555 \\
\hline 5 & 0.0481 & 13 & 0.8528 \\
\hline 6 & 0.1257 & 14 & 0.9249 \\
\hline 7 & 0.1940 & 15 & 0.9639 \\
\hline 8 & 0.2854 & 16 & 0.9787 \\
\hline
\end{tabular}

Reducing the voltage at low wind speed values such as 4 and $5 \mathrm{~m} / \mathrm{s}$ produces a losses increment. So, at such low wind speed values, rated voltage is considered, because no losses improvement can be reach by voltage reduction.

Table III shows similar results but taken now into account the soft starter losses. A $2 \%$ of the power flowing through the soft starter has been considered as it losses.

In order to determine the energy saving the power density curves must be determined. This is obtained multiplying 
the curve of the wind turbine power by the probability that the corresponding wind speed occurs.

$$
\operatorname{Power}(v)=P(v) \cdot P_{W I N D \text { POWER }}(v)
$$

Table IV shows the power density for every value of wind speed at the rated voltage for the analyzed case. Table V shows the power density for every value of wind speed at the optimum reduced voltage, including soft starter losses.

In order to evaluate the yearly energy saving the mean value of the generated power must be determined and then multiplied by the number of hours a year.

$$
\operatorname{Power}_{\text {MEAN }}=\int \operatorname{Power}(v) d v=\sum \operatorname{Power}(v) \Delta v
$$

This way, the yearly generated energy $(k W h)$, with and without voltage control, can be evaluated and compared. Figure 7 shows the power density (electric power injected in the transmission and distribution network) variation with the wind speed both for rated voltage supply and with optimum voltage control, for the analyzed wind generator.

Table IV. Values power density for every value of wind speed at the rated voltage.

\begin{tabular}{|c|c||c|c|}
\hline $\begin{array}{c}\text { Wind } \\
\text { Speed } \\
(\mathrm{m} / \mathrm{s})\end{array}$ & $\begin{array}{c}\text { Power } \\
\text { Density }\end{array}$ & $\begin{array}{c}\text { Wind } \\
\text { Speed } \\
(\mathrm{m} / \mathrm{s})\end{array}$ & $\begin{array}{c}\text { Power } \\
\text { Density }\end{array}$ \\
\hline 1 & 0 & 9 & 0.0227 \\
\hline 2 & 0 & 10 & 0.0255 \\
\hline 3 & 0 & 11 & 0.0263 \\
\hline 4 & 0.0009 & 12 & 0.0254 \\
\hline 5 & 0.0045 & 13 & 0.0232 \\
\hline 6 & 0.0088 & 14 & 0.0201 \\
\hline 7 & 0.0135 & 15 & 0.0165 \\
\hline 8 & 0.0184 & 16 & 0.0130 \\
\hline
\end{tabular}

Table V. Values power density for every value of wind speed at the optimum reduced voltage, including soft starter losses.

\begin{tabular}{|c|c||c|c|}
\hline $\begin{array}{c}\text { Wind } \\
\text { Speed } \\
(\mathrm{m} / \mathrm{s})\end{array}$ & $\begin{array}{c}\text { Power } \\
\text { Density }\end{array}$ & $\begin{array}{c}\text { Wind } \\
\text { Speed } \\
(\mathrm{m} / \mathrm{s})\end{array}$ & $\begin{array}{c}\text { Power } \\
\text { Density }\end{array}$ \\
\hline 1 & 0 & 9 & 0.0237 \\
\hline 2 & 0 & 10 & 0.0262 \\
\hline 3 & 0 & 11 & 0.0268 \\
\hline 4 & 0.0009 & 12 & 0.0257 \\
\hline 5 & 0.0045 & 13 & 0.0234 \\
\hline 6 & 0.0111 & 14 & 0.0202 \\
\hline 7 & 0.0154 & 15 & 0.0165 \\
\hline 8 & 0.0199 & 16 & 0.0131 \\
\hline
\end{tabular}

As can be seen, at low wind speed with optimum voltage control, less losses means more power available for the grid. For the analyzed case, the evaluation of the annual energy saving means an increase in the energy injected to the grid of $3.2 \%$.

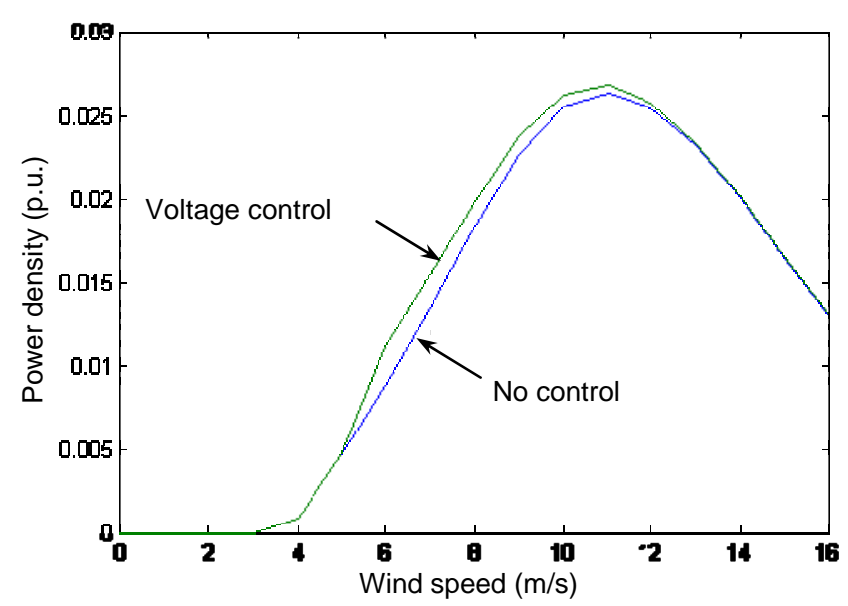

Fig. 7. Curve power density-wind speed for reduced voltage supply (green) and for rated voltage (blue).

$\operatorname{Power}_{\text {MEAN }}=\int \operatorname{Power}(v) d v=0.2190$
Power $_{\text {MEAN VOLTAGE CONTROL }}=\int \operatorname{Power}(v) d v=0.2261$

Energy Saving $=\frac{0.2261-0.2190}{0.2190}=0.032$

Similar results are obtained with the analysis of the reactive power.

\section{Wind farm performance improvement}

At low wind speeds (partial load), the voltage control improvement is not only limited to the induction generator losses and power factor. The improvement is reflected into the entire internal distribution network.

Figure 8 shows a typical wind farm electric diagram. A reduction in the stator current, $\boldsymbol{I}_{\mathbf{1}}$, , reduces the generator losses and the reactive power consumption, but this way the copper losses and the reactive power in every internal distribution line and transformer $(R, X)$ is reduced too.

$$
P^{\prime}=3 R\left|\boldsymbol{I}_{1}{ }_{1}\right|^{2} \quad Q^{\prime}=3 X\left|\boldsymbol{I}^{\prime}{ }_{1}\right|^{2}
$$

In the same way, the copper losses and the reactive power in the evacuation line $\left(R_{L}, X_{L}\right)$, related to the total current currents, $I^{\prime}=\sum \boldsymbol{I}_{1}^{\prime}$, is also reduced.

$$
P_{L}^{\prime}=3 R_{L}\left|\boldsymbol{I}^{\prime}\right|^{2} \quad Q_{L}^{\prime}=3 X_{L}\left|\boldsymbol{I}^{\prime}\right|^{2}
$$

A similar reduction in the copper losses and the reactive power is experienced by the wind farm substation transformer.

A word of caution about power factor improvement by voltage control is needed. The line-commutated thyristors of the soft-starter leads to a reduction of the power factor, which is higher for more reduced voltage. This negative side effect must be taken into account in the analysis because partially cancel the potential power factor improvement. 


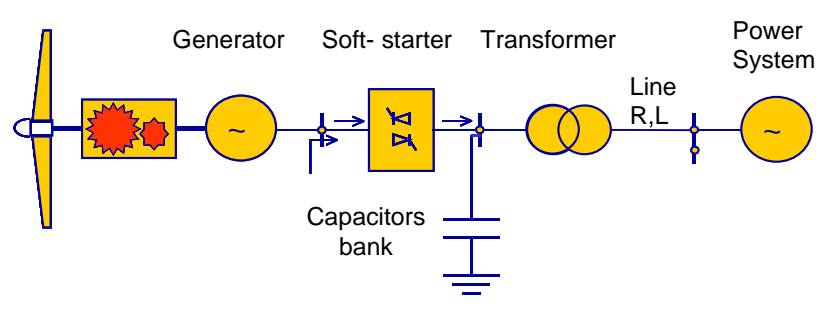

Fig. 8. Typical wind farm electric diagram.

\section{Conclusion}

When an induction generator at low wind speed or with light generated power is fed at optimum reduced voltage supply, some improvements are reached:

- A reduction of the iron losses proportional to the square of the voltage and, therefore, an efficiency improvement.

- A reduction of the stator current and, therefore, a reduction of the stator copper losses and in the energy evacuation lines and transformers.

- A reduction of the no load current or the magnetizing current and consequently a reduction of the power reactive demand and an improvement in the power factor.

- No additional costs are produced because wind turbine are provided with a soft starter device than could be use to control the voltage at low wind speeds.

Nevertheless, all these improvements are partially cancelled by some negative effects, such as:

- A voltage reduction leads to a higher slip value. This means an increase of the rotor copper losses.

- The static starter has its own losses, that although are small, must be considered in the analysis.
- The induction generator suffers a growing of the additional electrical and magnetic losses due to nonsine voltage and current supply (harmonics) that must be included in the analysis.

- The presence of harmonics in the wind farm network can adversely affect the power factor capacitor bank.

- The line-commutated soft-starter thyristors leads to a reduction of the power factor, which is higher for more reduced voltage.

For a more precise wind farm performance evaluation of the voltage control improvement, the internal distribution network impedances $(R, X)$ and transformer impedances should be included in the analysis.

\section{References}

[1] F.J. Nola, "Power Factor Controller - An Energy Saver", Proc. IEEE IAS Annual Meeting, 1980, pp. 194-198.

[2] F.J.T.E. Ferreira, A.T. de Almeida, "Method for In-Field Evaluation of the Stator Winding Connection of ThreePhase Induction Motors to Maximize Efficiency and Power Factor", IEEE Transactions on Energy Conversion, Vol. 212, June 2006 pp. 370 - 379.

[3] A.J.J. Rezek, C.A.D. Coelho, J.A. Cortez, J.M.E. Vicente, J.P.G. Abreu, C.D. Ramos, C. Megalhaes, V.F. da Silva, "Energy Conservation with Use of "Soft-Starter"", Proceedings. 9th I.C. on Harmonics and Quality of Power, Vol. 1, 1-4 Oct. 2000, pp. $354-359$.

[4] N. Mohan, "Improvement in Energy Efficiency of Inducting Motors by Means of Voltage Control", IEEE Transactions on Power App. and Systems, Vol. PAS-99, July/Aug. 1980, pp. 1466-1471.

[6] A. Kusko and D. Galler, "Control Means for Minimization of Losses in AC and DC Motor Drives", IEEE Trans. On Industry Applications, Vol. IA-19, No. 4, Nov./Dec. 1983, pp. 561-570.

[7] S. Heier, "Grid integration of wind energy conversion systems", John Wiley and Sons, 1998.

[8] N. Jenkins, "Electrical Design of Wind Farms", Proc. IEEE/NTUA Athens Power Tech Conference, Athens, Greece, pp. 990-994, Sep. 5-8, 1993.

[9] N. Jenkins, "Engineering Wind Farms", Power Engineering Journal, pp. 53-60, April, 1993. 